\title{
Difficulties encountered by public health workers in COVID-19 outbreak: a cross- sectional study based on five provinces
}

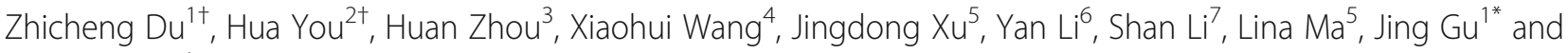
Yuantao $\mathrm{HaO}^{1}$

\begin{abstract}
Objectives: The aim of this study is to address the difficulties encountered by public health workers in the early and middle stages of their efforts to combat COVID-19, compare the gaps among different types of institutions, and identify shortcomings in epidemic control.

Methods: Using multi-stage sampling, a survey of public health workers involved in the prevention and control of COVID-19 was conducted from 18 February to 1 March 2020 through a self-administered questionnaire. These public health workers were from the primary health care center (defined as "primary-urban" and "primary-rural" for those in urban and rural areas, respectively) and the center for disease control and prevention (defined as "nonprimary") in five provinces including Hubei, Guangdong, Sichuan, Jiangsu and Gansu, China.

Results: A total of 9,475 public health workers were surveyed, of which $40.0 \%, 27.0 \%$ and $33.0 \%$ were from the primary-rural, primary-urban and non-primary, respectively. The resources shortage were reported by $27.9 \%$ participants, with the primary-rural being the worst affected ( $O R=1.201,95 \% \mathrm{Cl}: 1.073-1.345)$. The difficulties in data processing were reported by $31.5 \%$ participants, with no significant differences among institutions. The difficulties in communication and coordination were reported by $29.8 \%$ participants, with the non-primary being the most serious (primary-rural: $O R=0.520,95 \% \mathrm{Cl}: 0.446-0.606$; primary-urban: $O R=0.533,95 \% \mathrm{Cl}: 0.454-0.625$ ). The difficulties with target audiences were reported by $20.2 \%$ participants, with the primary-urban being the worst $(O R=1.368,95 \%$ Cl: 1.199-1.560). The psychological distress were reported by $48.8 \%$ participants, with no significant differences among institutions.

Conclusions: Psychological distress is the most serious problem in the prevention and control of COVID-19. Resources shortage in primary-rural, difficulties in communication and coordination in non-primary, and difficulties with target audiences in the primary-urban deserve attention. This study will provide scientific evidences for improving the national public health emergency management system, especially for reducing the urban-rural differences in emergency response capacity.
\end{abstract}

Keywords: Public health workers, Difficulties, COVID-19

\footnotetext{
* Correspondence: gujing5@mail.sysu.edu.cn

${ }^{\dagger}$ Zhicheng Du and Hua You contributed equally to this manuscript.

'School of Public Health, Global Health Institute, Key Laboratory of Tropical Disease Control, Sun Yat-sen University, 510080 Guangzhou, China Full list of author information is available at the end of the article
}

(c) The Author(s). 2021 Open Access This article is licensed under a Creative Commons Attribution 4.0 International License, which permits use, sharing, adaptation, distribution and reproduction in any medium or format, as long as you give appropriate credit to the original author(s) and the source, provide a link to the Creative Commons licence, and indicate if changes were made. The images or other third party material in this article are included in the article's Creative Commons licence, unless indicated otherwise in a credit line to the material. If material is not included in the article's Creative Commons licence and your intended use is not permitted by statutory regulation or exceeds the permitted use, you will need to obtain permission directly from the copyright holder. To view a copy of this licence, visit http://creativecommons.org/licenses/by/4.0/ The Creative Commons Public Domain Dedication waiver (http://creativecommons.org/publicdomain/zero/1.0/) applies to the data made available in this article, unless otherwise stated in a credit line to the data. 


\section{Introduction}

As of 12th April 2020, a total of 82,160 cases of COVID-19 had been diagnosed in China, and 3,341 cases had died [1]. By the date of 1st April 2020, the spread of COVID-19 in China has been basically interrupted [2]. All aspects of society and economy have been put to an unprecedented and severe test. As of 13th March 2020, China's investment in fighting the epidemic had reached 116.9 billion Chinese Yuan $(\approx 16.9$ billion US Dollar with the annual exchange rate in 2019 [3]), according to the State Council's joint prevention and control mechanism press conference [4].

As the COVID-19 was caused by a new coronavirus and spread extremely fast, the outbreak spread across the world in just a few months, with the number of infections and deaths rising rapidly. The medical manpower and material resources at the time were almost unable to cope with the sudden pandemic. Healthcare systems in all countries were under strain. As of 7th April 2020, the total number of medical staff assisting Hubei, China from other provinces has reached more than 42,600 [5]. There are also countless public health workers, community workers and volunteers who work on the front line of outbreak prevention and control.

In China, the main institutions providing public health services are Centers for Disease Prevention and Control (CDC), Health Education Centers (HEC) and Community Health Centers/stations $(\mathrm{CHC})$. In the rural areas, the township health centers and village health clinics assume the responsibilities of community health service centers/stations in the urban areas. China's public health service system is a top-down system with multiple tiers. Of these, the city level and above are usually referred to as "non-primary", and the level below city as "primary". During the COVID19 epidemic, the staff from the CDCs, HECs, and $\mathrm{CHCs}$ were mainly responsible for the prevention and control of the outbreak. These staff were defined as "public health workers" in our study, all of whom had a public health professional background or worked in public health and were paid by the government finance.

The public health workers are the important force in the fight against COVID-19 epidemic. They are responsible for carrying out zero-distance sampling and testing, epidemiological investigation, close contact tracing, outbreak analysis, disinfection of the public environment, and community prevention and control [6]. The COVID-19 epidemic, while a great stage victory, has also exposed shortcomings and deficiencies in our public health sectors. For example, President $\mathrm{Xi}$ pointed out that the first line of defence should be weaved tightly and firmly by strengthening primary capacity-building for prevention and control in rural and community areas. Some scholars have proposed that public health expenditure should be tilted towards backward areas, thereby narrowing the gap between urban and rural areas and regions in basic public health services and accelerating the process of equalization of basic public health services [7].

It is a major test for the national governance system and governance capacity to fight against the COVID-19 epidemic. In view of the shortcomings and deficiencies exposed by the epidemic,we should sum up the experience and learn from the lessons to tighten up the shortcomings, plug the loopholes and strengthen the weaknesses. The purpose of this study is to investigate the difficulties encountered by public health workers in the early and middle stages of the COVID-19 epidemic in China and compare between the primary and nonprimary levels. This study will identify shortcomings in epidemic prevention and control, and to provide scientific evidences for improving the national public health emergency management system.

\section{Materials and methods Study design}

This study was a cross-sectional study design using a self-administered questionnaire from February 18 to March 1, 2020 in five provinces including Hubei, Guangdong, Sichuan, Jiangsu and Gansu. These five provinces are located in Central China, South China, West China, East China and North China, with a cumulative number of confirmed cases (as of February 25) of 65,187, 1,347, 531, 631 and 91, respectively. The geographic locations of the five provinces were showed in Figure S1. The study was conducted using multi-stage targeted sampling (according to the severity of the epidemic and urban/rural distribution), with 3-6 cities within each province, 3-6 districts and 5-12 streets or communes within each city. In the sampled administrative areas, the staff from the CDCs and HECs at provincial, city and district levels and primary health care institutions (including community health centers/stations, township health centers, and village health clinics) involved in the prevention and control of COVID-19 epidemic were surveyed for this study. The relationship bewteen different levels and types health institutes (e.g., CDC, HEC and $\mathrm{CHC}$ ) in China were showed in Figure S2. We classified the surveyed institutions into 3 categories: CDCs and HECs (defined as "non-primary"), community health centers/stations in urban (defined as "primary-urban") and township health centers and village health clinics (defined as "primary-rural"). 


\section{Study subjects}

Inclusion criteria for the subjects of this study: (1) age 18 years and above; (2) public health workers involved in work related to COVID-19 outbreak prevention and control. This study distributed a web link containing the questionnaire via WeChat and QQ instant messenger. With the rigorous checking rules of network survey, the questionnaires we received were all valid. However, the response rate could not be computed as the population got the web link were unclear. All respondents were informed prior to the survey of the background, purpose, anonymity, and time required for the survey (approximately 8$12 \mathrm{~min})$. A self-administered questionnaire was administered with the consent of the survey respondents. This study was approved by the Ethics Committee of the School of Public Health, Sun Yatsen University (No. 2020-012).

\section{Survey content}

This study investigated demographic characteristics, epidemic prevention efforts, health status, encountered difficulties, perceptions of the epidemic, and emotional psychology. The questionnaire was self-designed through literature reviews, in-depth interviews, and focus-group sessions (Table S1). The elements used in this study are demographic characteristics, encountered difficulties and psychological distress. Demographic characteristics include 5 pieces of information: age, gender, child status (presence or absence of children and age of youngest child), job title, and type of institution (primary-rural, primary-urban, and non-primary). The encountered difficulties also included 5 dimensions: resources shortage (5 entries), data processing (5 entries), communication and coordination (4 entries), target audience (3 entries), and psychological distress (4 entries). The encountered difficulties dimensions were multiple-choice except for the psychological distress dimension, which used a 5-point Likert scale (the higher the score, the more severe the situation). We evaluated each dimension comprehensively using bicategorical variables, with the psychological distress dimension set to 1 (more distress) if the mean score was 2.5 (half of the maximum score of 5) or higher, and 0 otherwise, and the other dimension set to 1 (more difficulties) if half or more of the number of items were checked, and 0 otherwise.

\section{Statistical analysis}

The institution type was used as a grouping variable. Continuous variables (i.e., age) were described as mean \pm standard deviation (Mean $\pm S D$ ), and ANOVA was used for between-group comparisons. Qualitative variables were described as frequencies (proportions or rates) and compared between groups using Fisher's exact test. In the comprehensive analysis of encountered difficulties, logistic regression was used with bicategorical variables as dependent variable, institution type as independent variable, and the demographic characteristics as covariates. In addtion, we used the generalized linear mixed-effects model including the province as the random effect to exclude the potential variance among the provinces. All the analyses were performed at $P<0.05$ to indicate statistical significance.

\section{Results}

\section{Basic characteristics of study subjects}

A total of 9475 questionnaires were collected in this study, all of which were valid. Among them, 3786(40.0\%) were from primary-rural, $2561(27.0 \%)$ from primary-urban and $3128(33.0 \%)$ from non-primary. The average age was 38.7 years, with primary-rural being the oldest (39.9 years) and primary-urban being the youngest (36.4 years). The average percentage of females was $64.4 \%$, with the highest percentage in primary-rural $(78.25 \%)$ and the lowest percentage in non-primary $(58.12 \%)$. The average percentage of those without children or with children at primary level and below was $63.73 \%$, with the highest percentage in primary-urban $(77.20 \%)$ and the lowest in primary-rural $(53.01 \%)$. The average percentage of primary and below titles was $61.45 \%$, with the highest in primary-rural $(77.79 \%)$ and the lowest in non-primary $(45.62 \%)$. The differences in the above variables among the three groups were statistically significant (all $P<$ 0.001). (Table 1)

\section{Resources shortage}

We found that public health workers encounter multiple resource deficiencies in their work. Resources shortage were reported for protective gear $(87.4 \%)$, own skills (38.5\%), manpower (47.1\%), funding (20.3\%) and reagents $(8.0 \%)$. In particular, non-primary had a higher rate of reporting inadequate manpower and reagents than the primary (all $P<0.01$ ), and conversely, the primary had a higher rate of reporting inadequate protective equipment $(P<0.001)$. Comparing the two types of the primary institutions found that primary-urban had a higher rate of reporting inadequate protective equipment $(P=0.009)$, while primary-rural had a higher rate of reporting inadequate own skills, manpower, funding and reagents (all $P<0.01$ ). Among the protective equipment, deficiencies were reported, in descending order, for $\mathrm{N} 95$ masks $(80.5 \%)$, medical surgical masks $(80.4 \%)$, protective clothing $(77.5 \%)$, medical goggles $(57.0 \%)$, medical alcohol (47.9\%), forehead thermometers (43.6\%) and gloves (37.3\%). (Table 2) 
Table 1 Basic characteristics of the study subjects

\begin{tabular}{|c|c|c|c|c|c|}
\hline & Total & Primary-rural & Primary-urban & Non-primary & $P$ value \\
\hline Sample size & 9475 & 3786 & 2561 & 3128 & \\
\hline Age $(y)$ & $38.656 \pm 9.704$ & $39.891 \pm 10.123$ & $36.381 \pm 9.031$ & $39.022 \pm 9.395$ & $<0.001$ \\
\hline \multicolumn{6}{|l|}{ Sex } \\
\hline Male & $3378(35.65)$ & $1511(39.91)$ & $557(21.75)$ & $1310(41.88)$ & \multirow[t]{2}{*}{$<0.001$} \\
\hline Female & $6097(64.35)$ & $2275(60.09)$ & $2004(78.25)$ & $1818(58.12)$ & \\
\hline \multicolumn{6}{|l|}{ Child status } \\
\hline Absence & $2161(22.81)$ & $621(16.40)$ & $776(30.30)$ & $764(24.42)$ & \multirow[t]{3}{*}{$<0.001$} \\
\hline Primary school and below & 3877 (40.92) & $1386(36.61)$ & $1201(46.90)$ & $1290(41.24)$ & \\
\hline Junior high school and above & $3437(36.27)$ & $1779(46.99)$ & $584(22.80)$ & $1074(34.34)$ & \\
\hline \multicolumn{6}{|l|}{ Job title } \\
\hline Primary and below & $5822(61.45)$ & $2945(77.79)$ & $1450(56.62)$ & $1427(45.62)$ & \multirow[t]{3}{*}{$<0.001$} \\
\hline Intermediate & $2682(28.31)$ & $718(18.96)$ & $930(36.31)$ & $1034(33.06)$ & \\
\hline Advanced & $971(10.25)$ & $123(3.25)$ & $181(7.07)$ & $667(21.32)$ & \\
\hline \multicolumn{5}{|l|}{ Province } & \multirow[t]{6}{*}{$<0.001$} \\
\hline Sichuan & $3360(35.46)$ & $1812(47.86)$ & $610(23.82)$ & 938 (29.99) & \\
\hline Guangdong & $2812(29.68)$ & 455 (12.02) & $1559(60.87)$ & 798 (25.51) & \\
\hline Jiangsu & $1227(12.95)$ & $564(14.90)$ & $193(7.54)$ & 470 (15.03) & \\
\hline Hubei & 1401 (14.79) & 893 (23.59) & 135 (5.27) & 373 (11.92) & \\
\hline Gansu & $675(7.12)$ & $62(1.64)$ & $64(2.50)$ & 549 (17.55) & \\
\hline
\end{tabular}

Note: Continuous variables are expressed as mean \pm standard deviation and categorical variables are expressed as frequencies (proportions)

\section{Data processing}

We found that public health workers encountered difficulties in data processing in their work. The reported encountered difficulties in data processing were: excessive documentation (63.8\%), cumbersome and timeconsuming data filling (49.8\%), cumbersome and time- consuming work accounts (36.9\%), time-consuming transmission of information (25.7\%) and inconvenient transmission of documents (14.4\%). Among them, nonprimary had a higher rate of reporting encountered difficulties such as cumbersome and time-consuming data filling, time-consuming information reporting and

Table 2 Resources shortage between primary and non-primary institutions

\begin{tabular}{|c|c|c|c|c|c|c|c|}
\hline & $\begin{array}{l}\text { Total } \\
n(\%)\end{array}$ & $\begin{array}{l}\text { Primary- } \\
\text { rural } \\
(\%)\end{array}$ & $\begin{array}{l}\text { Primary- } \\
\text { urban } \\
(\%)\end{array}$ & $\begin{array}{l}\text { Non- } \\
\text { primary } \\
(\%)\end{array}$ & $P$ value & $\begin{array}{l}\text { Primary } \\
\text { vs. } \\
\text { Non-primary } \\
P \text { value* }\end{array}$ & $\begin{array}{l}\text { Primary-rural } \\
\text { vs. } \\
\text { Primary-urban } \\
P \text { value* }\end{array}$ \\
\hline Protective equipment & $8280(87.39)$ & 90.62 & 92.50 & 79.28 & $<0.001$ & $<0.001$ & 0.009 \\
\hline Self-skill & $3645(38.47)$ & 43.16 & 28.47 & 40.98 & $<0.001$ & $<0.001$ & $<0.001$ \\
\hline Manpower & $4459(47.06)$ & 45.69 & 41.66 & 53.13 & $<0.001$ & $<0.001$ & 0.002 \\
\hline Funding & $1927(20.34)$ & 24.64 & 14.76 & 19.69 & $<0.001$ & 0.278 & $<0.001$ \\
\hline Reagents & $761(8.03)$ & 8.80 & 5.23 & 9.40 & $<0.001$ & 0.001 & $<0.001$ \\
\hline \multicolumn{8}{|l|}{ Protective equipment } \\
\hline N95 mask & $6663(80.49)$ & 76.61 & 80.71 & 85.65 & $<0.001$ & $<0.001$ & $<0.001$ \\
\hline Surgical masks for medical use & $6654(80.38)$ & 81.54 & 81.43 & 77.78 & 0.001 & $<0.001$ & 0.918 \\
\hline Protective clothing & $6419(77.54)$ & 76.03 & 82.57 & 74.84 & $<0.001$ & $<0.001$ & $<0.001$ \\
\hline Medical goggles & $4714(56.95)$ & 63.43 & 58.08 & 46.90 & $<0.001$ & $<0.001$ & $<0.001$ \\
\hline Medical alcohol & $3964(47.89)$ & 53.40 & 46.01 & 42.06 & $<0.001$ & $<0.001$ & $<0.001$ \\
\hline Epidural gun & $3611(43.62)$ & 56.87 & 38.88 & 29.84 & $<0.001$ & $<0.001$ & $<0.001$ \\
\hline Medical gloves & 3088 (37.30) & 44.94 & 35.46 & 28.51 & $<0.001$ & $<0.001$ & $<0.001$ \\
\hline
\end{tabular}

*The $P$ values were corrected for multiple comparisons. "Total" column was presented as frequency (reporting rate). "Primary-rural", "Primary-urban", and "Nonprimary" columns were presented as reporting rates 
inconvenient document information transmission than the primary (all $P<0.01$ ). Comparing the two types of primary institutions found no statistical difference in the reported rate of encountered difficulties in data processing. (Table 3)

\section{Communication and coordination}

We found that public health workers encounter a variety of hard situations in their communication and coordination work. Difficulties in communication and coordination were reported as poor inter-agency coordination $(35.3 \%)$, poor intra-departmental coordination $(28.1 \%)$, unclear assignments from superiors (18.4\%), and unclear overtime incentive system $(40.6 \%)$. Of these, all of the above encountered difficulties were higher reported by non-primary compared with the primary-rural and primary-urban (all $P<0.001$ ). Comparing the two types of primary institutions found that primary-urban had a higher rate of reporting encountered difficulties with poor intradepartmental coordination $(P<0.001)$. (Table 3$)$

\section{Target audience}

We found that outbreak prevention and control workers encounter a variety of hard situations with the target audience they work with. The rates of reported difficulties with target audience were: uncooperative $(40.1 \%)$, verbal abuse/intimidation by work targets $(13.7 \%)$, and concerns about survey reliability $(36.0 \%)$. Of these, non-primary had a higher rate of reporting concerns about survey reliability than the primary $(P<0.001)$. Comparing the two types of primary institutions found that primary-urban had a higher rate of reporting difficulties with uncooperative and verbal abuse/intimidation by work targets $(P<0.001)$. (Table 3)

\section{Psychological distress}

We found that the public health workers encountered multiple situations of psychological distress in their work. The levels of each type of psychological distress were: being treated differently at work (2.4 points), feeling aggrieved at work ( 2.6 points), family members not understanding (1.9 points) and worrying about routine work outside of the epidemic (2.6 points). Among them, non-primary had higher levles of being treated differently at work and feeling aggrieved at work than the primary (both $P<0.001$ ). While the primary had higher levels of worrying about routine work outside of the epidemic $(P=0.003)$. Comparing the two types of primary institutions found that primary-urban had a higher rate of reporting distress with family members not understanding $(P=0.002)$, and primary-rural had a higher rate of reporting distress with worrying about routine work outside of the epidemic $(P=0.003)$. (Table 4$)$

Table 3 Difficulties in data processing, communication and coordination, and target audiences between primary and non-primary institutions

\begin{tabular}{|c|c|c|c|c|c|c|c|}
\hline & $\begin{array}{l}\text { Total } \\
n(\%)\end{array}$ & $\begin{array}{l}\text { Primary- } \\
\text { rural } \\
(\%)\end{array}$ & $\begin{array}{l}\text { Primary- } \\
\text { urban } \\
(\%)\end{array}$ & $\begin{array}{l}\text { Non- } \\
\text { primary } \\
(\%)\end{array}$ & $P$ value & $\begin{array}{l}\text { Primary } \\
\text { vs. } \\
\text { Non-primary } \\
P \text { value* }\end{array}$ & $\begin{array}{l}\text { Primary-rural } \\
\text { vs. } \\
\text { Primary-urban } \\
P \text { value* }\end{array}$ \\
\hline \multicolumn{8}{|l|}{ Data processing } \\
\hline Excessive documentation & $6040(63.75)$ & 63.63 & 63.84 & 63.81 & 0.982 & 0.946 & 0.946 \\
\hline Cumbersome and time-consuming data filling & $4720(49.82)$ & 47.99 & 49.39 & 52.37 & 0.002 & 0.001 & 0.282 \\
\hline Cumbersome and time-consuming work accounts & $3500(36.94)$ & 37.64 & 35.85 & 36.99 & 0.362 & 0.946 & 0.305 \\
\hline Time-consuming transmission of information & $2433(25.68)$ & 23.77 & 22.10 & 30.91 & $<0.001$ & $<0.001$ & 0.122 \\
\hline Inconvenient transmission of documents & $1367(14.43)$ & 12.86 & 12.26 & 18.09 & $<0.001$ & $<0.001$ & 0.488 \\
\hline \multicolumn{8}{|l|}{ Communication and coordination } \\
\hline Poor inter-agency coordination & $3346(35.31)$ & 26.70 & 36.70 & 44.60 & $<0.001$ & $<0.001$ & $<0.001$ \\
\hline Poor intra-departmental coordination & $2091(22.07)$ & 19.31 & 18.74 & 28.13 & $<0.001$ & $<0.001$ & 0.580 \\
\hline Unclear assignments from superiors & $1740(18.36)$ & 14.53 & 15.97 & 24.97 & $<0.001$ & $<0.001$ & 0.116 \\
\hline Unclear overtime incentive system & $3851(40.64)$ & 36.90 & 36.78 & 48.34 & $<0.001$ & $<0.001$ & 0.937 \\
\hline \multicolumn{8}{|l|}{ Target audiences } \\
\hline Uncooperative & $3800(40.11)$ & 39.28 & 46.47 & 35.90 & $<0.001$ & $<0.001$ & $<0.001$ \\
\hline Verbal abuse/intimidation by work targets & $1297(13.69)$ & 12.57 & 18.00 & 11.51 & $<0.001$ & $<0.001$ & $<0.001$ \\
\hline Concerns about survey reliability & $3402(35.91)$ & 34.57 & 35.38 & 37.95 & 0.019 & 0.008 & 0.520 \\
\hline
\end{tabular}

*The $P$ values were corrected for multiple comparisons. "Total" column was presented as frequency (reporting rate). "Primary-rural", "Primary-urban", and "Nonprimary" columns were presented as reporting rates 
Table 4 Psychological distress between primary and non-primary institutions

\begin{tabular}{|c|c|c|c|c|c|c|c|}
\hline & $\begin{array}{l}\text { Total } \\
M \pm S D\end{array}$ & $\begin{array}{l}\text { Primary- } \\
\text { rural } \\
M \pm S D\end{array}$ & $\begin{array}{l}\text { Primary- } \\
\text { urban } \\
M \pm S D\end{array}$ & $\begin{array}{l}\text { Non- } \\
\text { primary } \\
M \pm S D\end{array}$ & $\begin{array}{l}P \\
\text { value }\end{array}$ & $\begin{array}{l}\text { Primary } \\
\text { vs. } \\
\text { Non- } \\
\text { primary } \\
P \text { value* }\end{array}$ & $\begin{array}{l}\text { Primary-rural } \\
\text { vs. } \\
\text { Primary- } \\
\text { urban } \\
P \text { value* }\end{array}$ \\
\hline Being treated differently at work & $2.437 \pm 0.984$ & $2.395 \pm 1.002$ & $2.383 \pm 0.909$ & $2.527 \pm 1.013$ & $<0.001$ & $<0.001$ & 0.741 \\
\hline Feeling aggrieved at work & $2.572 \pm 1.003$ & $2.539 \pm 1.013$ & $2.506 \pm 0.945$ & $2.665 \pm 1.029$ & $<0.001$ & $<0.001$ & 0.405 \\
\hline Family members not understanding & $1.867 \pm 0.883$ & $1.849 \pm 0.904$ & $1.903 \pm 0.867$ & $1.857 \pm 0.870$ & 0.046 & 0.654 & 0.002 \\
\hline $\begin{array}{l}\text { Worrying about routine work outside of the } \\
\text { epidemic }\end{array}$ & $2.640 \pm 0.990$ & $2.692 \pm 0.999$ & $2.608 \pm 0.963$ & $2.604 \pm 0.999$ & $<0.001$ & 0.003 & 0.003 \\
\hline
\end{tabular}

* The $P$ values were corrected for multiple comparisons. $\mathrm{M} \pm \mathrm{SD}$ indicates mean \pm standard deviation

\section{Comprehensive analysis}

All five dimensions of encountered difficulties were reported at a relative high rate (20.2-48.8\%). The difference in reporting rates were statistically significant among institutions for resources shortage, coordination and communication, and target audience. Of these, resources shortage was more frequently reported in primary-rural $(O R=1.201,95 \% C I$ : 1.073-1.345); Difficulties in communication and coordination in nonprimary were reported at higher rates (primary-rural: $O R=0.520,95 \% C I: 0.446-0.606$, primary-urban: $O R=$ 0.533, $95 \% C I$ : 0.454-0.625); Primary-rural reported higher rates in difficulties with target audience $(O R=$ 1.368, $95 \% C I$ : 1.199-1.560). Consistent results were obtianed from the generalized linear mixed-effects models. (Table 5)

\section{Discussions}

This study, based on a survey of 9,475 public health workers, explored possible shortcomings in the early and middle stages of major outbreak prevention and control work, and found that the highest reporting rate was psychological distress $(48.8 \%)$, the middle reporting rate was data processing $(31.25 \%)$, communication and coordination $(29.8 \%)$ and resource shortage (27.9\%), and the lowest reporting rate was target audience (20.2\%). A comparative analysis among different institutions found higher rates of resources shortage in primary-rural,

Table 5 Comparative analysis of the five dimensions of encountered difficulties between primary and non-primary institutions

\begin{tabular}{|c|c|c|c|c|c|}
\hline & $\begin{array}{l}\text { Resources shortage } \\
\text { OR(95\% } \% \mathrm{Cl})\end{array}$ & $\begin{array}{l}\text { Data processing } \\
\text { OR(95 \%Cl) }\end{array}$ & $\begin{array}{l}\text { Communication and } \\
\text { coordination } \\
\text { OR(95\%Cl) }\end{array}$ & $\begin{array}{l}\text { Target audiences } \\
\text { OR(95\% \% })\end{array}$ & $\begin{array}{l}\text { Psychological distress } \\
\text { OR(95\%Cl) }\end{array}$ \\
\hline \multicolumn{6}{|c|}{ Institution, reporting rate (\%) } \\
\hline Total & 27.9 & 31.5 & 29.8 & 20.2 & 48.8 \\
\hline Non-primary & 28.8 & 34.1 & 40.9 & 19.6 & 50.7 \\
\hline Primary-rural & 32.1 & 30.6 & 22.8 & 18.4 & 48.0 \\
\hline Primary-urban & 20.7 & 29.6 & 26.8 & 23.4 & 47.5 \\
\hline \multicolumn{6}{|l|}{ Unadjusted } \\
\hline \multicolumn{6}{|c|}{ Institution (ref.= Non-primary) } \\
\hline Primary-rural & $1.171(1.056,1.298)^{* *}$ & $0.850(0.768,0.940)^{* *}$ & $0.389(0.338,0.448)^{* * *}$ & $0.927(0.822,1.046)$ & $0.899(0.818,0.988)^{*}$ \\
\hline Primary-urban & $0.643(0.569,0.728)^{* * *}$ & $0.812(0.726,0.909)^{* * *}$ & $0.458(0.393,0.534)^{* * *}$ & $1.253(1.103,1.422)^{* *}$ & $0.880(0.793,0.977)^{*}$ \\
\hline \multicolumn{6}{|l|}{ Adjusted $1^{a}$} \\
\hline \multicolumn{6}{|c|}{ Institution (ref.= Non-primary) } \\
\hline Primary-rural & $1.201(1.073,1.345)^{* *}$ & $1.010(0.904,1.129)$ & $0.520(0.446,0.606)^{* * *}$ & $1.085(0.952,1.237)$ & $0.996(0.898,1.104)$ \\
\hline Primary-urban & $0.713(0.629,0.810)^{* * *}$ & $0.916(0.815,1.029)$ & $0.533(0.454,0.625)^{* * *}$ & $1.368(1.199,1.560)^{* *}$ & $0.901(0.809,1.003)$ \\
\hline \multicolumn{6}{|l|}{ Adjusted $2^{b}$} \\
\hline \multicolumn{6}{|c|}{ Institution (ref.= Non-primary) } \\
\hline Primary-rural & $1.311(1.163,1.478)^{* * *}$ & $0.990(0.882,1.111)$ & $0.596(0.529,0.671)^{* * *}$ & $1.146(0.999,1.315)$ & $1.068(0.958,1.190)$ \\
\hline Primary-urban & $0.728(0.636,0.833)^{* * *}$ & $0.871(0.769,0.987)^{*}$ & $0.560(0.494,0.635)^{* * *}$ & $1.282(1.114,1.475)^{* *}$ & $0.924(0.824,1.037)$ \\
\hline
\end{tabular}

${ }^{\mathrm{a}}$ The variables including age, gender, child status and job title were adjusted

${ }^{\mathrm{b}}$ The variables including age, gender, child status and job title were adjusted, as well as the province was included as a random effect ${ }^{*} P<0.05,{ }^{* *} P<0.01,{ }^{* * *} P<0.001$ 
higher rates of communication and coordination in nonprimary, and higher rates of target audience in primaryurban.

The mental health problems of public health workers cannot be ignored. The psychological distress was found as the most serious in this study, with a reporting rate of nearly half $(48.8 \%)$. And there was no variation among institutions, suggesting that despite the differences in the content of outbreak prevention and control work in different institutions, all faced high levels of psychological distress. Mental health problems of clinical staff in outbreak prevention and control have raised concern [8]. This study found that the mental health problems of public health workers are also of concern, and further explored their specific sources of distress, such as: being treated differently at work, feeling aggrieved at work, family members not understanding and worrying about routine work outside the epidemic. $\mathrm{Li}$ et al. found a higher reported rate of depression (21.3\%) and anxiety (19.0\%) among the public health workers in COVID-19 epidemic [9]. The mental health impact of the first wave of COVID-19 pandemic on Spanish healthcare workers were also reported with a prevalence of $28.1 \%$ in major depressive Dissorder [10]. Similarly, $28.4 \%$ healthcare workers in Spain were found with a medium-high emotional load or extreme acute stress [11]. These psychological distresses directly affect epidemic prevention on the one hand, and pose mental health hazards to staff on the other. In the future, the comprehensive protection of public health workers should be improved [12], and humanistic care should be strengthened so that they can work with peace of mind and efficiency [13]. In addition, the current psychological intervention for epidemic workers focuses on clinical health care staff, and the psychological relief and intervention for public health workers cannot be ignored.

The problem of resources shortage in primary-rural is of concern. The resources shortage problem found in this study is serious (27.9\% reporting rate) and the highest reporting rate in primary-rural, suggesting that resources allocation in primary-rural needs to be optimized in the early and middle stages of epidemic. Moreover, a previous study showed that at least $70 \%$ healthcare workers reported a lack of personal protective equipment including gown coverall suits, N95 masks, and face shields [14]. Admittedly, the resources shortage in China occurred mainly in the early stage of epidemic. Because with the development of the epidemic, the capacity and transfer of epidemic prevention materials work in an orderly manner, which gradually ensure that China's reserve materials are sufficient. Resources shortage was mainly manifested in insufficient emergency material reserves and the capacity of health emergency response teams needs to be improved. Government financial support for health emergencies should be increased and the allocation of resources for health emergencies optimized. Vulnerable areas with relatively insufficient financial support (e.g., the primary-rural identified in this study) are often the focus of health emergency work. The introduction, training and training of health emergency staff should be strengthened, and drills and training in on-site epidemiological investigation are important ways to improve health emergency response capacity [15].

Difficulties in communication and coordination in non-primary institutions need attention. The difficulties in communication and coordination found in this study are serious (the reporting rate is $29.8 \%$ ), and the highest reporting rate is found in non-primary, suggesting that the reform of China's CDC institutions needs to pay attention to information communication and transportation coordination. As the core backbone of the public health network, the work of CDC institutions involves more communication and coordination. Difficulties in communication and coordination are mainly manifested in unclear overtime incentive system and poor communication between and within departments, which will directly affect the implementation of epidemic prevention and control and its effectiveness. To address difficulties in communication and coordination, we should put the staff overtime incentive performance programs [16] and the multi-departmental joint prevention and control mechanisms at different levels [17] into the construction of the emergency system for public health emergencies.

Difficulties with target audiences in primary-urban were relatively prominent. The difficulties with target audiences found in this study were relatively serious (the reporting rate is $20.2 \%$ ), and the reporting rate is highest in primary-urban, suggesting that the focus of public education on public health in China should be on primary-urban. Difficulties with target audiences are mainly manifested in concerns about the reliability of the survey and the uncooperative, which will directly affect the effect of blocking the transmission route and protecting vulnerable groups in epidemic prevention and control. In order to address the difficulties with target audiences, vigorous efforts should be made to promote community awareness of public health and emergency work, so that the community can understand the relevant work, reduce misunderstandings and promote prevention and control work. For key populations with a lower level of education, we should use appropriate methods to publicize and popularize core information on the prevention and control of infectious diseases, cultivate their good hygiene habits and healthy lifestyles, and raise the overall population's awareness of the prevention and control of infectious diseases [18]. 
There are limitations to this study. First, the multistage sampling according to geographic distribution and the severity of the epidemic may be subject to selection bias, leading to an increased risk of extrapolating the findings to other parts of the country. Second, this study used a self-administered questionnaire, which may be subject to reporting bias. Third, this study was a crosssectional survey and it cannot yet be assumed that the shortcomings identified were only in the context of preventing and controlling the COVID-19 epidemic.

\section{Conclusions}

In summary, China's epidemic prevention and control personnel have played an important role in the fight against the COVID-19 epidemic. We found that the most serious in the prevention and control work was psychological distress. The resources shortage in primary-rural, the difficulties in communication and coordination in non-primary, and the difficulties with target audiences in primary-urban were worthy of attention. This study will provide a scientific basis for improving the national public health emergency management system, especially for reducing the urban-rural disparity in emergency response capacity.

\section{Supplementary Information}

The online version contains supplementary material available at https://doi. org/10.1186/s12913-021-06699-4.

\section{Additional file 1.}

\section{Acknowledgements}

We thank all public health workers who completed the survey and all the agencies that coordinated the research sites.

\section{Authors' contributions \\ $J G, Y H$, and ZD conceived the research questions, designed the quesionnaire, assembled the team of collaborators, and conducted quality control. HY, HZ, XW, JX, YL, SL and LM coordinated the field work and collected data. ZD conducted the statistical analysis. ZD and JG drafted the manuscript. YH revised the manuscript and gave scientific comments. ZD and JG finalized the manuscript. All authors assisted in questionnaire design, data collection, data interpretation, and gave comments to intellectual content of the manuscript. The author(s) read and approved the final manuscript.}

\section{Funding}

This work was supported by the Sun Yat-sen University 2020 "Three Major" Construction Major Scientific Research Projects Cultivation Project.

\section{Availability of data and materials}

The datasets during and/or analysed during the current study available from the corresponding author on reasonable request.

\section{Declarations}

\section{Ethics approval and consent to participate}

This study was approved by the Ethics Committee of the School of Public Health, Sun Yat-sen University (No. 2020-012). All methods were carried out in accordance with relevant guidelines and regulations. All participants were informed of the background, aims, anonymous nature and length of the survey. Participants were well informed that completing the questionnaire signified their informed consent. The informed consent was obtained from all participants.

Consent for publication

Not applicable.

\section{Competing interests}

The authors declare that they have no competing interests.

\section{Author details}

'School of Public Health, Global Health Institute, Key Laboratory of Tropical Disease Control, Sun Yat-sen University, 510080 Guangzhou, China. ${ }^{2}$ School of Public Health, Nanjing Medical University, 210000 Nanjing, China. ${ }^{3}$ West China School of Public Health, West China Fourth Hospital, Sichuan University, 610000 Chengdu, China. ${ }^{4}$ School of Public Health, Lanzhou University, 730000 Lanzhou, China. ${ }^{5}$ Hubei Provincial Center for Disease Control and Prevention, 430097 Wuhan, China. ${ }^{6}$ Guangzhou Center for Disease Control and Prevention, 510440 Guangzhou, China. ${ }^{7}$ Zigong Center for Disease Control and Prevention, 643000 Zigong, China.

Received: 10 February 2021 Accepted: 24 June 2021

Published online: 05 July 2021

\section{References}

1. National Health Commission of the People's Republic of China. Update on the outbreak of COVID-19 on 12 April[EB/OL]. (2020-04-13) [2020-04-13]: http://www.nhc.gov.cn/xcs/yqtb/202004/ee6750d722a54876872056e6aa fd5822.shtml.

2. People's Daily Online. The spread of the epidemic throughout the country has been largely blocked[EB/OL]. (2020-04-01) [2020-04-13]: http://paper. people.com.cn/rmrb/html/2020-04/01/nw.D110000renmrb_20200401_5-03. htm.

3. National Bureau of Statistics of China. China Statistical Yearbool[EB/OL]. [2021-03-28]: http://www.stats.gov.cn/tjsj/ndsj/2020/indexch.htm.

4. Xinhua Net. Financial investment in epidemic prevention and control has reached 116.9 billion yuan[EB/OL]. (2020-03-14) [2020-04-13]: https://weibo. com/1699432410/lyzNzd6R3?from=page_1002061699432410_profile\&wvr= $6 \&$ mod=weibotime\&type $=$ comment\# rnd1586764903998.

5. Tencent. The National Health Committee: nearly $70 \%$ of the medical staff in aid to Hubei; female nurses accounted for $90 \%$ [EB/OL]. (2020-04-07) [202008-10]: https://xw.qq.com/amphtml/20200407A0KCU600.

6. National Health Commission of the People's Republic of China. Notice of the General Office of the National Health Commission on Further Strengthening the Publicity of the Sensational Deeds of Public Health Workers in the Prevention and Control of the New Coronary Pneumonia Epidemic[EB/OL]. (2020-03-06) [2020-04-13]: http://www.nhc.gov.cn/xcs/ s7851/202003/53de0ab571f44b36bc560e86504f3954.shtml.

7. Chi F. Putting people's health at the centre and deepening public health system reform[EB/OL]. (2020-03-25) [2020-04-13]: http://paper.ce.cn/jjrb/ html/2020-03/25/content_415459.htm.

8. Kang L, Li Y, Hu S, Chen M, Yang C, Yang BX, Wang Y, Hu J, Lai J, Ma X, Chen J, Guan L, Wang G, Ma H, Liu Z. The mental health of medical workers in Wuhan, China dealing with the 2019 novel coronavirus[J]. The Lancet Psychiatry, 2020, 7(3): e14. DOl: https://doi.org/10.1016/S2215-0366(20)3004 $7-X$.

9. Li J, Xu J, Zhou H, You H, Wang X, Li Y, Liang Y, Li S, Ma L, Zeng J, Cai H, Xie J, Pan C, Hao C, Gilmour S, Lau JT, Hao Y, Xu DR, Gu J. Working conditions and health status of 6,317 front line public health workers across five provinces in China during the COVID-19 epidemic: a cross-sectional study[J]. BMC PUBLIC HEALTH, 2021, 21(1): 106. DOI: https://doi.org/10.1186/ s12889-020-10146-0.

10. Alonso J, Vilagut G, Mortier P, Ferrer M, Alayo I, Aragón-Peña A, Aragonès E, Campos M, Cura-González ID, Emparanza JI, Espuga M, Forjaz MJ, GonzálezPinto A, Haro JM, López-Fresneña N, Salázar ADMD, Molina JD, Ortí-Lucas RM, Parellada M, Pelayo-Terán JM, Pérez-Zapata A, Pijoan Jl, Plana N, Puig MT, Rius C, Rodríguez-Blázquez C, Sanz F, Serra C, Kessler RC, Bruffaerts R, Vieta E, Pérez-Solà V. Mental health impact of the first wave of COVID-19 pandemic on Spanish healthcare workers: A large cross-sectional survey[J]. Revista de Psiquiatría y Salud Mental, 2020, DOl: https://doi.org/10.1016/j. rpsm.2020.12.001 
11. Mira JJ, Carrillo I, Guilabert M, Mula A, Martin-Delgado J, Pérez-Jover MV, Vicente MA, Fernández C. Acute stress of the healthcare workforce during the COVID-19 pandemic evolution: a cross-sectional study in Spain[]]. BMJ OPEN, 2020, 10(11): e42555. DOI: https://doi.org/10.1136/bmjopen-2020-042 555.

12. Mira JJ, Vicente MA, Lopez-Pineda A, Carrillo I, Guilabert M, Fernández C, Pérez-Jover V, Martin Delgado J, Pérez-Pérez P, Cobos Vargas A, Astier-Peña MP, Martínez-García OB, Marco-Gómez B, Abad Bouzán C. Preventing and Addressing the Stress Reactions of Health Care Workers Caring for Patients With COVID-19: Development of a Digital Platform (Be + Against COVID)[J]. JMIR MHEALTH UHEALTH, 2020, 8(10): e21692. DOl: https://doi.org/10.21 96/21692.

13. Shen $W$, Qin $Y$, Tao M, Li Z, Chen X, Chen N. A Survey on the Mental Health Levels of Frontline Medical Staff in Hunan Province for the Prevention and Control of Novel Coronavirus Pneumonia Outbreak (In Chinese)[j]. Chinese General Practice Nursing, 2020, 18(8): 957-962. DOI: https://doi.org/10.121 04/j.issn. 1674-4748.2020.08.055

14. Martin-Delgado J, Viteri E, Mula A, Serpa P, Pacheco G, Prada D, Campos De Andrade Lourenção D, Campos Pavan Baptista P, Ramirez G, Mira JJ. Availability of personal protective equipment and diagnostic and treatment facilities for healthcare workers involved in COVID-19 care: A cross-sectional study in Brazil, Colombia, and Ecuador[]]. PLOS ONE, 2020, 15(11): e242185.

15. Zhang T, Wang C, Li J, Dong Y. Systematic evaluation of the current assessment of contemporary public health emergency response capacity and management responses (In Chinese)[]]. China Health Standard Management, 2019, 10(2): 32-35. DOl: https://doi.org/10.3969/j.issn.1674-931 6.2019 .02 .014

16. Yi S. Overtime compensation systems in China and abroad, on all sides (In Chinese)[]]. Finance \& Accounting of Chinese Trade Unions, 2016, (3): 39-41.

17. QIU W, CHU C, MAO A, DONG P, DING H, YAN X, U GH, MENG Y, YANG Y,

WU J. Multisectoral cooperation in the prevention and control of SARS and H7N9 avian influenza outbreak in China (In Chinese)[J]. Journal of Public Health and Preventive Medicine, 2019, 30(1): 1-4.

18. Wu Y, Nan H, Tie Y, Guo J. Analysis of the Current Situation and Influencing Factors of Infectious Disease Prevention and Control Literacy among Residents of Shaanxi Province (In Chinese)[]]. Infectious Disease Information, 2019, 32(5): 407-410

\section{Publisher's Note}

Springer Nature remains neutral with regard to jurisdictional claims in published maps and institutional affiliations.

Ready to submit your research? Choose BMC and benefit from:

- fast, convenient online submission

- thorough peer review by experienced researchers in your field

- rapid publication on acceptance

- support for research data, including large and complex data types

- gold Open Access which fosters wider collaboration and increased citations

- maximum visibility for your research: over $100 \mathrm{M}$ website views per year

At $\mathrm{BMC}$, research is always in progress.

Learn more biomedcentral.com/submissions 